\title{
The likely consequences of vaping bans
}

\author{
Gilbert Berdine MD
}

Recently the state of New York followed the example of Michigan and banned sales of flavored electronic cigarettes. ${ }^{1}$ The ban will be in effect for 90 days. The legislation includes a sunset provision, so the ban must be renewed or extended by government action in order to continue. The only flavors of electronic cigarettes permitted under the ban are tobacco and menthol. The state of New York is considering additional restrictions on menthol.

This action follows an emergency investigation by the Centers for Disease Control (CDC) on lung injury associated with electronic cigarettes. ${ }^{2}$ This investigation was apparently triggered by the $7^{\text {th }}$ death attributed to electronic cigarettes. The New York ban was a response to this CDC action as well as to reports of 74 confirmed cases of lung injury attributable to electronic cigarettes. ${ }^{1}$ The stated goal of the ban is to save lives. The questions, however, are whether this goal will be realized and whether unintended harms will be worse than any benefit achieved. The remainder of this article will consider other causes of death to answer these questions.

Motor vehicle accidents accounted for 40,231 deaths in the United States in 2017. ${ }^{3}$ Motor vehicles represent a far greater hazard to the public than electronic cigarettes. Should we ban motor vehicles? We have not banned motor vehicles because the benefits of motor vehicles are too obvious and clearly preferable to the risks of motor vehicles. The number of deaths due to motor vehicles was only 4,200 in 1913. A ban on motor vehicles in 1913 might very well have reduced fatalities attributable to motor vehicles. However, by any number of metrics, motor vehicles are much safer today than

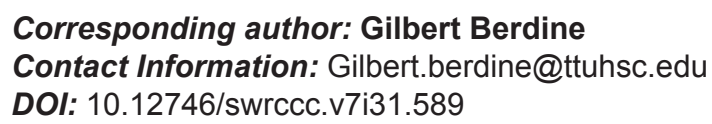

in 1913 . The fatality rate per 10,000 motor vehicles was 33.38 in 1913 and has declined to 1.47 in 2017. This improvement in safety is due to safer cars, safer tires, and safer roads. The research, development, testing, and capital investment necessary to achieve these safety improvements would never have occurred had motor vehicles been banned. The capital investments were made possible by the potential for much greater use of motor vehicles by the public in the future.

The appropriate response to the reports of fatalities attributable to electronic cigarettes is to determine why these fatalities are emerging now. Are the cases of lung injury due to impurities? If so, a ban will make the production of safer electronic cigarettes going forward very unlikely. The only suppliers of electronic cigarettes would be criminals who have a very short term focus and have no incentive to improve quality control. Are the cases of lung injury due to some rare side effect of the electronic cigarette and are appearing due to increasing use? If so, bans will make it impossible for courts to assess damages to manufacturers. If electronic cigarettes have a statistical rate of complications, then manufacturers will have to factor in damages as part of the business model. Courts would determine how much blame should go to the manufacturer, how much to the distributor, and how much to individuals who choose to vape in light of evidence of possible harm. There would be an incentive to all the parties involved to minimize the risk of harm. Manufacturers would have incentives to produce electronic cigarettes with lower complication rates. Distributors would have incentives to ensure that customers know what they are buying and the risks attached to their purchases. The individuals choosing to vape would have incentives to be better informed about the risks of vaping and alternatives to vaping. The capital investment necessary to achieve these improvements will occur only if manufacturers have a long term outlook. Bans or the 
threat of bans will cause the outlook of manufacturers to become shorter term; the manufacturers would behave more and more like criminal suppliers of cocaine.

The National Institutes of Health $(\mathrm{NIH})$ estimates that 88,000 deaths in the United States annually are attributable to alcohol consumption. ${ }^{4}$ We tried a ban on alcohol (Prohibition) and it did not turn out too well. We gave up on Prohibition because the unintended harmful side effects of Prohibition were far worse than any perceived benefits.

Why do people use electronic cigarettes? If electronic cigarettes are banned, will people substitute worse behaviors for vaping? Some people use electronic cigarettes to help quit cigarette smoking. According to the CDC cigarette smoking was responsible for more than 480,000 deaths per year in the United States. ${ }^{5}$ Electronic cigarettes have been tolerated by the Food and Drug Administration (FDA) due to the possible reductions in cigarette smoking by the availability of electronic cigarettes. The CDC report further states that each day over 2,000 people under the age of 18 smoke their first cigarette and over 300 people under the age of 18 become daily cigarette smokers. ${ }^{5}$ Government agencies have become increasingly concerned about the use of electronic cigarettes by people under the age of 18 , but a ban on electronic cigarettes may lead to more young people dying from cigarettes than would die from electronic cigarettes.

According to the CDC the age-adjusted suicide rate was 14.0 per 100,000 U.S. population in 2017 . It is at least plausible that there is overlap between the causes of suicide, the causes of cigarette smoking, and the causes of vaping. There are insufficient data to claim correlation, but it should be considered that bans on vaping may increase the number of suicides beyond any reductions in deaths attributable to vaping. Human action serves a purpose. People do things in order to achieve goals. People smoke or vape for reasons. We do not adequately understand the reasons. Some patients who try to quit smoking report relapse during periods of tension or stress. The cause of stress can be death or illness in the family, problems with social relationships, unemployment, or many other things. It is plausible that smoking or vaping serves as an emotional relief valve for these stresses. If one means of stress relief, such as vaping, is made illegal then it would be plausible that more people would choose alternative means of handling stress including the drastic means of suicide. It is not a foregone conclusion that a ban on vaping would increase suicide, but an increase in suicide is a plausible outcome of a ban on vaping.

At the current time, deaths and serious illness attributable to vaping are uncommon. We should try to keep things that way. Bans on vaping will likely prevent the improved safety in electronic cigarettes that should emerge over time. Bans on vaping will lead to the emergence of unsafe supply by criminal elements. Bans on vaping may cause far greater numbers of deaths due to cigarette smoking and/or suicide than any reductions of deaths attributable to electronic cigarettes. Society would be better served by studying the causes of vaping as well as the mechanisms of lung injury from vaping.

Keywords: electronic cigarettes, vaping, legislation, morbidity, mortality

Article citation: Berdine G. The likely consequences of vaping bans. The Southwest Respiratory and Critical Care Chronicles 2019;7(31):67-69

From: Department of Internal Medicine, Texas Tech University Health Sciences Center, Lubbock, Texas

Submitted: 9/20/2019

Accepted: 9/20/2019

Conflicts of interest: none

This work is licensed under a Creative Commons Attribution-ShareAlike 4.0 International License.

\section{REFERENCES}

1. Christensen B. New York State bans most flavors of e-cigarettes. CNN. September 17, 2019. https://www.cnn.com/2019/09/17/ health/new-york-ban-on-flavored-e-cigarettes/index.html

2. CDC News Release. Investigation of lung injury associated with e-cigarette product use, or vaping. September 16, 2019. https://www.cdc.gov/media/releases/2019/s0916-eoc-lunginjury.html 
3. Injury facts. car crash deaths and rates: National Safety Council. 2019. https://injuryfacts.nsc.org/motor-vehicle/historicalfatality-trends/deaths-and-rates/

4. National Institute of Alcohol Abuse and Alcoholism: Alcohol Facts and Statistics. August 2018. https://www.niaaa.nih.gov/ alcohol-facts-and-statistics
5. Fast Facts: Diseases and Death. Diseases and Death. Centers for Disease Control and Prevention. https://www.cdc.gov/ tobacco/data_statistics/fact_sheets/fast_facts/index.htm

6. Hedegaard H, Curtin SC, Warner M. Suicide mortality in the United States, 1999-2017. NCHS Data Brief No. 330, November 2018. https://www.cdc.gov/nchs/products/databriefs/db330.htm 